\title{
Reassessment of the Role of Saprophytic Activity in the Ecology of Thielaviopsis basicola
}

\author{
M. E. Hood and H. D. Shew
}

Department of Plant Pathology, North Carolina State University, Raleigh 27695.

Accepted for publication 21 August 1997.

\section{ABSTRACT}

Hood, M. E., and Shew, H. D. 1997. Reassessment of the role of saprophytic activity in the ecology of Thielaviopsis basicola. Phytopathology 87:1214-1219.

The ability of Thielaviopsis basicola to survive saprophytically in soil was investigated using root tissue from susceptible hosts as organic substrates. Inoculum densities were lower in soils amended with root tissue than in nonamended controls after 2 and 4 weeks of incubation. The greatest decrease occurred in soils containing the highest concentration of root tissue or in soils in which root tissue included the soluble components of the living root. Reproduction by $T$. basicola also was examined in axenic media containing either killed root pieces or various carbohydrates as the sole carbohydrate source. T. basicola utilized killed root tissue as a carbohydrate source in axenic media, particularly in cultures in which root tissue included the soluble components. Enzymatic activities of T. basicola, however, did not result in maceration of the root tissue. T. basicola utilized sucrose and cellobiose, but did not utilize structural carbohydrates such as cellulose, hemicellulose, or pectin. Based on the absence of significant saprophytic ability, T. basicola should be classified ecologically as an obligate parasite.
Thielaviopsis basicola (synanamorph Chalara elegans) is a soilborne, plant-pathogenic fungus commonly found in agricultural and nonagricultural soils $(39,40)$. A wide range of economically important plants are parasitized by $T$. basicola (22), resulting in black root rot. In addition to these host plants, T. basicola is found in association with the roots of numerous weed and native plant species $(9,40)$ and persists in soils that have been out of cultivation for many years (33).

The significant impact of $T$. basicola on crop production has led to extensive study of this organism, and concepts of its mode of pathogenesis and ecology are well established. T. basicola is generally considered to be a weak or facultative parasite (8), implying the ability to survive long periods in the absence of a host by saprophytic utilization of soilborne organic matter. The organism's ubiquitous presence in soil (40), its extremely wide host range (22), and the ease of culturing in standard axenic media (29) are largely responsible for this concept. T. basicola was classified as a primitive, soil-inhabiting fungus by Garrett (8) and Subramanian (35), and this description, no doubt, has influenced the direction of research efforts to control populations of $T$. basicola and losses to black root rot. Observations of the interactions of $T$. basicola with other microorganisms and organic matter, however, do not agree with predictions based upon this ecological concept; $T$. basicola is sensitive to microbial antagonism $(1,4,28,30)$, and organic soil amendments and the cultivation of nonhosts have a negative or neutral effect on populations of $T$. basicola $(1,3,15,23,27,31,36)$.

T. basicola recently has been classified as a hemibiotroph (12, 13,21). Biotrophic pathogenesis on host roots involves differentiation of fungal structures similar to haustoria that invaginate the plasma membrane of the living host cell (13). As intracellular hyphae grow from these structures, the integrity of the host cell is breached and necrosis occurs $(12,13,21)$. Production of primary inoculum occurs concurrently with the onset of host necrosis and is considered to indicate a necrotrophic phase $(7,18)$.

Corresponding author: H. D. Shew; E-mail address: d_shew@ncsu.edu

Publication no. P-1997-1006-01R

(C) 1997 The American Phytopathological Society
The objective of the current study was to reexamine the saprophytic ability of $T$. basicola, specifically on roots of susceptible hosts, and to evaluate the current ecological classification of this fungus.

\section{MATERIALS AND METHODS}

Fungal isolate, culture maintenance, and inoculum production. An isolate of T. basicola ( $\mathrm{SH}-2)$, obtained from diseased roots of burley tobacco (Nicotiana tabacum) (29), was used in all experiments of this study. The isolate was morphologically typical of wild-type isolates of T. basicola and similar to other isolates in the level of aggressiveness on tobacco in pathogenicity tests conducted under greenhouse conditions. The isolate was periodically inoculated onto burley tobacco roots and re-isolated following symptom development to avoid adverse effects of growth in culture on pathogen aggressiveness. An additional isolate of T. basicola was used in the survival experiment of this study. This isolate (COT-10) was obtained from diseased roots of cotton and was pathogenic on cotton in greenhouse tests. Cultures of both isolates were maintained on $5 \%$ carrot agar $(50 \mathrm{ml}$ of canned carrot extract [Hollywood carrot extract; Pet, Inc., St. Louis] and $18 \mathrm{~g}$ of agar/liter of deionized water) at 22 to $25^{\circ} \mathrm{C}$ in the dark.

Endoconidia were harvested by washing 2-week-old colonies of T. basicola with $2 \mathrm{ml}$ of sterile, deionized water. Endoconidia were trapped on a sterile, 0.2- $\mu \mathrm{m}$ syringe filter (Nalgene, Rochester, NY), rinsed with $10 \mathrm{ml}$ of deionized water, and resuspended in deionized water. The concentration of endoconidia was determined with a hemacytometer and diluted to 10,000 endoconidia/ml with deionized water.

Aleuriospores (chlamydospores) were harvested by blending in deionized water mycelial mats scraped from 3-week-old cultures. The resulting suspension was poured through nested sieves of 53and $25-\mu \mathrm{m}$ grid sizes to separate aleuriospores from hyphae and endoconidia (29). Aleuriospores were rinsed on the $25-\mu \mathrm{m}$ sieve under a stream of deionized water and resuspended in deionized water. The concentration of aleuriospores was determined with a hemacytometer and diluted to 10,000 aleuriospores $/ \mathrm{ml}$ with deionized water. 
Survival in amended soil. The survival of $T$. basicola was examined in pasteurized greenhouse soil amended with killed host roots. Roots of susceptible cultivars of tobacco (Burley $21 \times$ Kentucky 10) and cotton (Deltapine 50) were obtained from 2-monthold seedlings grown under greenhouse conditions. The roots were washed free of soil with deionized water, cut into about $1-\mathrm{cm}$ pieces (excluding the tap roots), and blotted twice between layers of filter paper to remove excess water. Blotted root pieces were autoclaved $\left(15 \mathrm{~min}\right.$ at $121^{\circ} \mathrm{C}$ ) either submerged in deionized water $(1: 1,000 \mathrm{wt} / \mathrm{wt})$ (wet) or as small clumps suspended in beakers by self-clasping forceps (dry).

Soil (soil/sand/MetroMix [Scotts-Sierra Horticultural Products Co., Marysville, $\mathrm{OH}] ; 1: 1: 1)$ was dried at $102^{\circ} \mathrm{C}$ for $12 \mathrm{~h}$ and then wetted with the inoculum suspension to result in $10 \%$ (wt/wt) soil moisture $(35 \mathrm{kPa})$ and an inoculum density of 1,000 spores of $T$. basicola/g of dry soil. Infested soil was amended with 3.0, 0.3, or $0.0 \%$ root tissue $(\mathrm{wt} / \mathrm{wt})$ of either wet or dry autoclaved roots; the weight of the root tissue was determined for blotted root pieces prior to autoclaving. Each isolate of T. basicola was used to infest only nonamended soil or soil amended with root tissue of its respective host. Infested amended soil $(7.5 \mathrm{~g})$ was added to each of 10 small glass vials per treatment and incubated at 22 to $25^{\circ} \mathrm{C}$ in the dark. Vials were capped loosely to allow air exchange, and soil moisture was adjusted back to $10 \%$ by weight at 48 -h intervals; evaporation of water caused the soil moisture content to drop from $10 \%$ to about $8.5 \%(65 \mathrm{kPa})$ during the $48-\mathrm{h}$ intervals.

Inoculum densities of $T$. basicola were determined for four vials per treatment after 2 and 4 weeks of incubation by a modification of a selective soil plating technique $(29,32)$. The entire contents of a vial $(7.5 \mathrm{~g})$ were mixed in a blender for $20 \mathrm{~s}$ with $112.5 \mathrm{ml}$ of deionized water. Four milliliters of the soil/root suspension were removed, while blending, and added to $96 \mathrm{ml}$ of molten selective media; the soil suspension for each vial was subsampled three times. The selective medium contained 5\% carrot juice, $1.8 \%$ agar, and an aqueous suspension of antibiotics as described by Specht and Griffin (32). The $100 \mathrm{ml}$ of selective medium and soil suspension was swirled and poured into a $15 \times 150-\mathrm{mm}$ plastic petri dish. Colonies were counted after dishes were incubated for 14 days at 22 to $25^{\circ} \mathrm{C}$ in the dark. Treatments were replicated four times per run and assigned in a completely randomized design. The test was run twice with endoconidia of the tobacco isolate as inoculum and twice with aleuriospores of the tobacco isolate as inoculum. The test was run once with aleuriospores of the cotton isolate as inoculum. Data were analyzed by GLM procedures of SAS (SAS Institute, Cary, NC) and combined across runs when possible, and significant differences were determined by Waller-Duncan $K$ ratio test $(K=100)$.

Two replications per run also were included so that root pieces could be examined microscopically for hyphal forms or reproductive structures characteristic of $T$. basicola $(12,13)$, and four replications per run were included for bioassay of soil upon completion of the experiment. Root pieces were sampled after 2 and 4 weeks of incubation and treated with a $\mathrm{KOH}$-aniline blue fluorescence method for staining hyphae (11). Aqueous soil extracts were prepared after 4 weeks of incubation from two of the replications intended for soil bioassay: (i) soil from each vial was agitated in $10 \mathrm{ml}$ of deionized water for $5 \mathrm{~min}$ and allowed to settle; (ii) the supernatant was filter-sterilized with a sterile, $0.2-\mu \mathrm{m}$ syringe filter (Nalgene), and $1 \mathrm{ml}$ was added to each well of a 24-well plate (Becton Dickinson, Rutherford, NJ); (iii) $10 \mu \mathrm{l}$ of endoconidial suspension (about 10 endoconidia/ $\mu$ ) was added to the wells, and the plates were incubated at 22 to $25^{\circ} \mathrm{C}$ in the dark; and (iv) fungal growth was examined after $48 \mathrm{~h}$ of incubation using an inverted microscope. Three-week-old tobacco seedlings were transplanted to soil from the additional two replications intended for soil bioassay, and roots of the seedlings were examined for black root rot symptoms 1 week after transplant.
Axenic utilization of killed root tissue. Reproduction of $T$. $b a$ sicola was determined in a liquid medium containing segments of killed host roots as the sole source of carbohydrate. The basal medium for culture of $T$. basicola was similar to that described by Stover (34) and Treggi et al. (37) and consisted of 1 liter of deionized water, $1 \mathrm{~g}$ of $\mathrm{KH}_{2} \mathrm{PO}_{4}, 0.5 \mathrm{~g}$ of $\mathrm{MgSO}_{4} \cdot 7 \mathrm{H}_{2} \mathrm{O}, 0.5 \mathrm{~g}$ of $\mathrm{KCl}$, $5 \mu \mathrm{g}$ of $\mathrm{FeCl}_{2}, 1.33 \mathrm{~g}$ of glycine, and $100 \mu \mathrm{g}$ of thiamine hydrochloride, $\mathrm{pH}$ 6.0. One milliliter of this medium was added to each well of a 24-well plate, and a 1-cm piece of killed tobacco root was placed in the medium. Tobacco roots were obtained from plants grown in an axenic-aeroponics system. The aeroponics system was entirely autoclavable, circulated full-strength Hoagland's solution (Sigma Chemical Co., St. Louis) via a small peristaltic pump, and contained a $0.2-\mu \mathrm{m}$ filtered air vent for gas exchange. Sterile tobacco seedlings (Burley $21 \times$ Kentucky 10) were prepared as described by Hood and Shew (13) and transferred to the aeroponics system after 1 month of growth in petri dishes. Roots were harvested after 2 weeks of growth in the aeroponics system, and 1-cm apical pieces were rinsed in sterile, deionized water and then killed by one of the following means: quick frozen on a sterilized, $-80^{\circ} \mathrm{C}$ metal surface; autoclaved wet as described above; or autoclaved dry as described above. In addition, senescent roots were included in this study and were obtained from plants cultured in one-tenth strength Hoagland's solution for 9 months in petri dishes. The frozen and the autoclaved dry roots were expected to retain more of the soluble components of the living host cells than roots that were autoclaved wet or those that were senescent. Ten microliters of endoconidial suspension (about 10 endoconidia/ $\mu$ l) was added to the wells, and the plates were incubated at 22 to $25^{\circ} \mathrm{C}$ in the dark. Cultures of $T$. basicola were fixed after 14 days of incubation by adding $50 \mu \mathrm{l}$ of $25 \%$ glutaraldehyde to each well. The contents of each well were homogenized with a small-volume glass homogenizer, and the concentration of spores was determined with a hemacytometer. The test was run twice with the tobacco isolate, with four replications per run, and treatments were assigned in a completely random design.

Two replications of each treatment also were included per run to allow microscopic examination of root specimens upon completion of the experiment, and four wells per run were included to which 1-month-old cultured tobacco seedlings were added to allow observation of parasitic development under the experimental conditions.

Axenic utilization of structural carbohydrates. Reproduction of $T$. basicola was determined in synthetic media containing one of various structural carbohydrates (carbohydrates that compose the cell walls of plants) as the sole carbon source. The basic medium for culture of T. basicola was prepared as described above. Carbohydrates (Sigma Chemical Co.) used in this study included cellulose, carboxymethyl cellulose (soluble), hemicellulose (locust bean gum), and pectin. Sucrose, cellobiose, and the absence of a carbohydrate were used as controls (37). Carbohydrates were added to the basal medium at concentrations of $0.01,0.10$, and $1.00 \%$ carbohydrate (wt/wt). The acidity of these media was not adjusted, but was between 5.6 and 5.9 for media containing any carbohydrate except pectin; pectin media were $\mathrm{pH} 5.6,4.7$, or 4.0 at the 0.01 , 0.10 , or $1.00 \%$ concentrations, respectively. Ten microliters of endoconidial suspension (about 5 endoconidia/ $\mu$ ) was added to wells of a 24-well plate (each well contained $1 \mathrm{ml}$ of medium), and the plates were incubated at 22 to $25^{\circ} \mathrm{C}$ in the dark. Cultures of $T$. basicola were fixed after 14 days of incubation by adding $50 \mu \mathrm{l}$ of $25 \%$ glutaraldehyde to each well as described above. The quantification of endoconidia in cellulose-containing media and in the medium with the highest concentration of hemicellulose was not possible because of the inability to differentiate the hyaline spores from the insoluble contents of the wells. The test was run twice with the tobacco isolate, with four replications per run, and treatments were assigned in a completely random design. 


\section{RESULTS}

Survival in amended soil. The amendment of soil with dead host root tissue negatively affected survival of $T$. basicola compared with nonamended control treatments (Fig. 1). Results were similar across isolates and with both inoculum types, but the inoculum densities after incubation were substantially lower when endoconidia (data not shown) were used as inoculum than when aleuriospores were used. Inoculum densities did not increase in any treatments amended with dead tobacco roots. The greatest reduction in inoculum density occurred in soil that contained the highest concentration of root tissue and in soil that contained root tissue that was autoclaved dry. With the cotton isolate, using aleuriospores as inoculum, the inoculum densities after 2 weeks of incubation were $143 \mathrm{CFU} / \mathrm{g}$ of soil in the nonamended control soil, $80 \mathrm{CFU} / \mathrm{g}$ in soil that contained 0.3 or $3.0 \%$ wet autoclaved
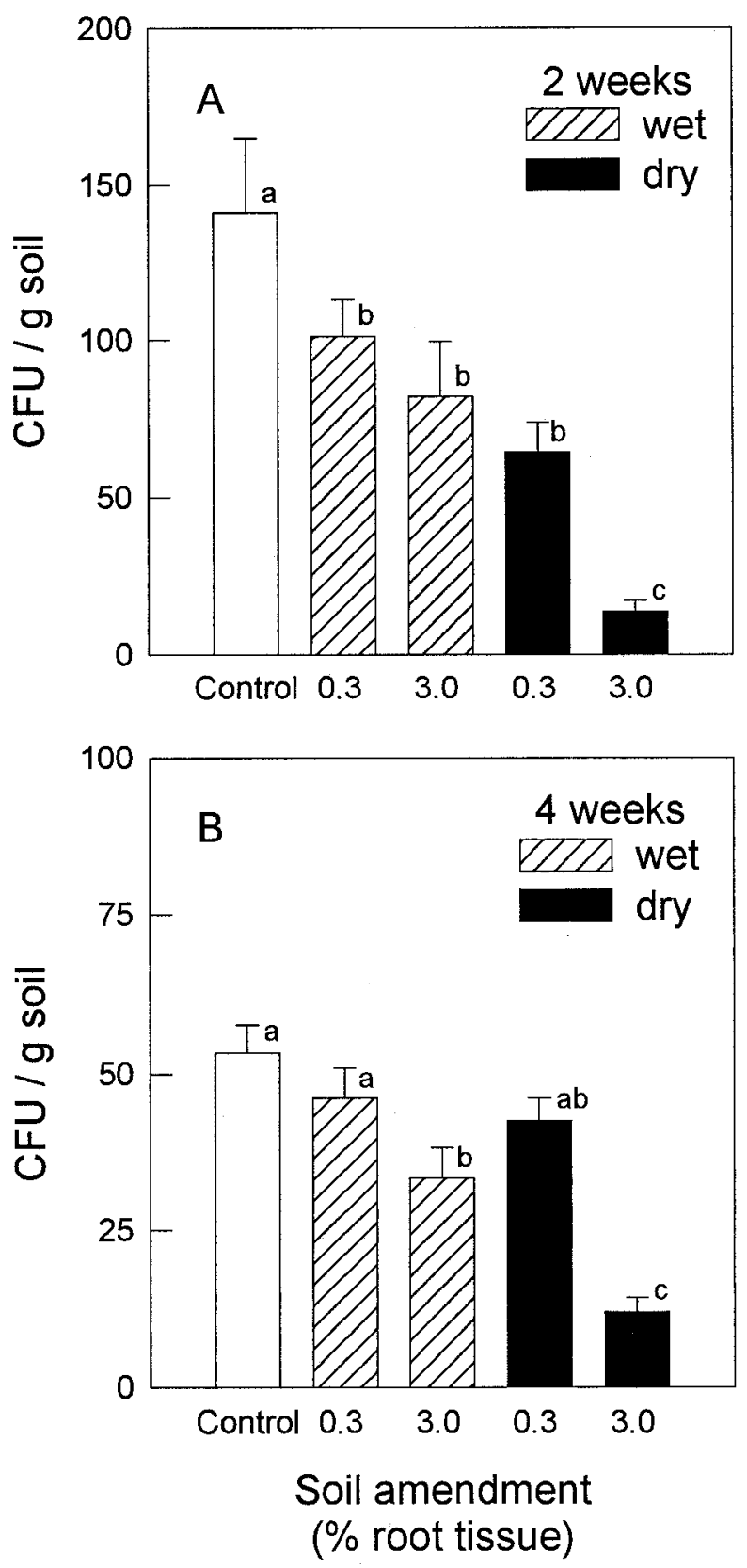

Fig. 1. Survival of aleuriospores of the tobacco isolate of Thielaviopsis basicola in pasteurized greenhouse soil amended with killed tobacco roots. Error bars $=$ standard error of the mean of eight replications. Means were compared using the Waller-Duncan $K$ ratio test. A, Inoculum densities after 2 weeks of incubation. B, Inoculum densities after 4 weeks of incubation. roots, and 51 or $45 \mathrm{CFU} / \mathrm{g}$ in soil that contained 0.3 or $3.0 \%$ dry autoclaved roots, respectively.

Hyphal forms and reproductive structures characteristic of $T$. basicola were not observed in association with dead root pieces after 2 or 4 weeks of incubation in infested soil, but numerous unidentified fungi grew and sporulated on the dead root pieces. Bioassays performed after 4 weeks of incubation with soils containing the amendments or the nonamended control did not indicate any fungistatic effects of amendment with dead root tissue. Cultures of $T$. basicola appeared to grow equally well in soil extracts prepared from each soil, and tobacco seedlings became diseased (black root rot) when they were planted in soil, regardless of treatment. All plants developed lesions, but those in nonamended soil and in soil containing $0.3 \%$ autoclaved dry roots had more lesions than those planted in soil with other amendments.

Axenic utilization of killed root tissue. T. basicola demonstrated the ability to utilize dead host root tissue in axenic culture (Fig. 2). Aleuriospore production was greater in media with killed root tissue than in the basal medium alone, and production was greatest in media that contained higher concentrations of the soluble root components (frozen and autoclaved dry treatments). Production of endoconidia was not affected by the presence of the root tissue.

Hyphal forms associated with parasitic development of $T$. basicola were not observed upon microscopic examination of killed root specimens from axenic culture. In fact, the growth and reproduction of $T$. basicola in the wells was not associated with the root tissue. The fungus grew in the surrounding media as frequently as on the root pieces, particularly in the frozen and autoclaved dry treatments. In addition, killed root pieces were not macerated or structurally degraded by enzymatic activities of $T$. basicola during the experiment. Parasitic development on living host roots under axenic conditions also did not result in observable maceration or structural degradation of host tissue, even though prolific growth and sporulation were associated with the root.

Axenic utilization of structural carbohydrates. $T$. basicola did not efficiently utilize (using spore production as a measure of nutrient utilization) the structural carbohydrates present in synthetic

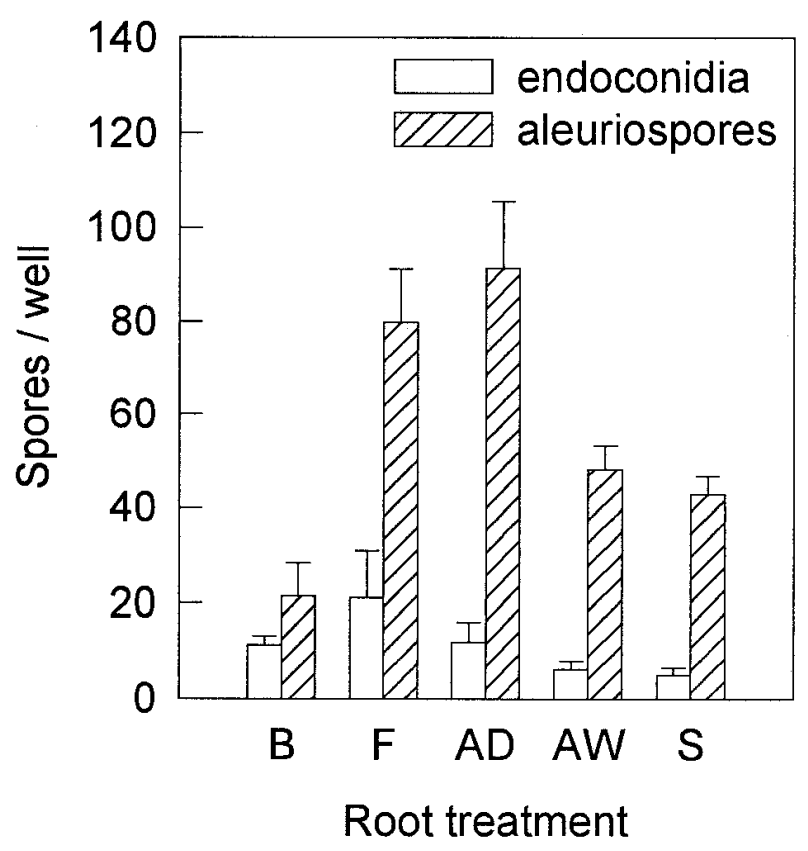

Fig. 2. Reproduction of Thielaviopsis basicola after 4 weeks of incubation in axenic media containing killed tobacco roots. Error bars $=$ standard error of the mean of eight replications. Treatments include control treatment without root piece (B), root pieces killed by freezing $(\mathrm{F})$, root pieces killed by autoclaving dry (AD), root pieces killed by autoclaving wet (AW), and senescent root pieces $(\mathrm{S})$. 
media compared with utilization of simple carbohydrate controls (sucrose and cellobiose) (Fig. 3). The type of spore produced varied with the simple carbohydrate; endoconidia were predominantly produced in sucrose and aleuriospores in cellobiose.

\section{DISCUSSION}

Efforts to limit agronomic losses to diseases caused by fungi are often based upon an understanding of how the pathogen survives in its natural environment. For example, measures that prevent the establishment of a parasitic relationship are more effective at reducing inoculum densities when saprophytic survival is not possible for the pathogen. The cultivation of various nonhost plants either decreases populations of $T$. basicola or has no effect compared with fallow soils $(3,15,27,36)$. Populations of $T$. basicola in soils would be expected to increase, however, or to at least be maintained at higher levels than in fallow soil if T. basicola had the ability to compete saprophytically for the additional organic matter derived from nonhost roots. For this reason, Bateman (3) suggested that the saprophytic behavior of $T$. basicola was restricted to an association with roots of host plants. In addition, cultivation of nonhost plants in rotation with host crops has been effective at lowering populations of $T$. basicola compared with host monoculture $(2,10,15,20)$. The interactions of $T$. basicola with nonhosts indicate poor competitive saprophytic ability.

Organic amendment of soil also results in a reduction of $T$. basicola inoculum density. Of 23 amendments tested by Papavizas (23), only glucose, sucrose, and several nitrogen sources increased inoculum densities of $T$. basicola. All other amendments had a negative or neutral effect on inoculum densities. Additional studies have provided similar results $(1,24,31)$. Reduction of inoculum densities was attributed to a stimulation of propagule germination and subsequent lysis due to microbial antagonism $(1,4,6,24,31,32)$. T. basicola is sensitive to antagonism by other soilborne microorganisms $(1,4,28,30)$, and germ tubes and hyphae are short-lived outside of a parasitic association with a susceptible host $(1,4,5)$. Because soil-inhabiting fungi are able to competitively colonize dead organic substrates (8), the addition of organic matter from a broad spectrum of sources should not result in the reduction of inoculum densities of such fungi. Therefore, the description of $T$. basicola as a soil-inhabiting fungus, or as a weak or facultative parasite, does not follow from observations of interactions of the organism with biotic factors and organic matter in the soil environment.

Although T. basicola has been considered to have saprophytic ability $(8,9,19,29,33,35)$, the evidence is generally circumstantial. The very wide host range of $T$. basicola and the ability to culture the organism in standard axenic media are characteristics of fungi considered to be nonobligate parasites $(7,8)$. However, the use of culturability in axenic media may be a poor criterion for ecological classification of fungi (16), because the environment, particularly biotic factors, has tremendous influence on the ability of organisms to secure organic substrates. The unspecialized trait of parasitizing diverse plant taxa is not as easily discarded, and the evolutionary history of $T$. basicola that has resulted in such an adaptation deserves further investigation. A wide host range, however, is not evidence of saprophytic ability and, moreover, may partially explain the presence of $T$. basicola in many agricultural and nonagricultural soils. Stover (33) assumed that T. basicola exists partially as a saprophyte in the absence of a susceptible host, because the organism persisted in soils that were out of cultivation for several decades. This observation also may be explained, however, by the wide host range of $T$. basicola and the ability to parasitize weed species that become established in the noncultivated fields. Specific reports of saprophytic behavior by $T$. basicola in soil are limited $(9,19)$. Gayed (9) based his conclusions of saprophytic behavior by $T$. basicola on recovery of the organism from organic residues from infested fields and the ability of $T$. basicola to utilize green leaf tissue as a nutrient source in vitro. The ability of $T$. basicola to utilize green leaf tissue is expected, considering the organism is known to parasitize foliar plant tissues (5), and the concentrated application of inoculum and incubation of specimens in humidified petri dishes (9) may have provided suitable conditions for development of T. basicola. Maier (19) amended soil with organic matter from several sources and reported that the addition of barley straw slightly increased populations of $T$. basicola following infection of bean, but did not increase disease severity over nonamended controls. The increase in inoculum density was suggested to have resulted from barley straw providing a suitable substrate for saprophytic development of $T$. basicola. However, amendment of soil with barley straw was included among treatments of Papavizas (23) and Snyder et al. (31), in which the amendment decreased populations of $T$. basicola and black root rot of bean. Linderman
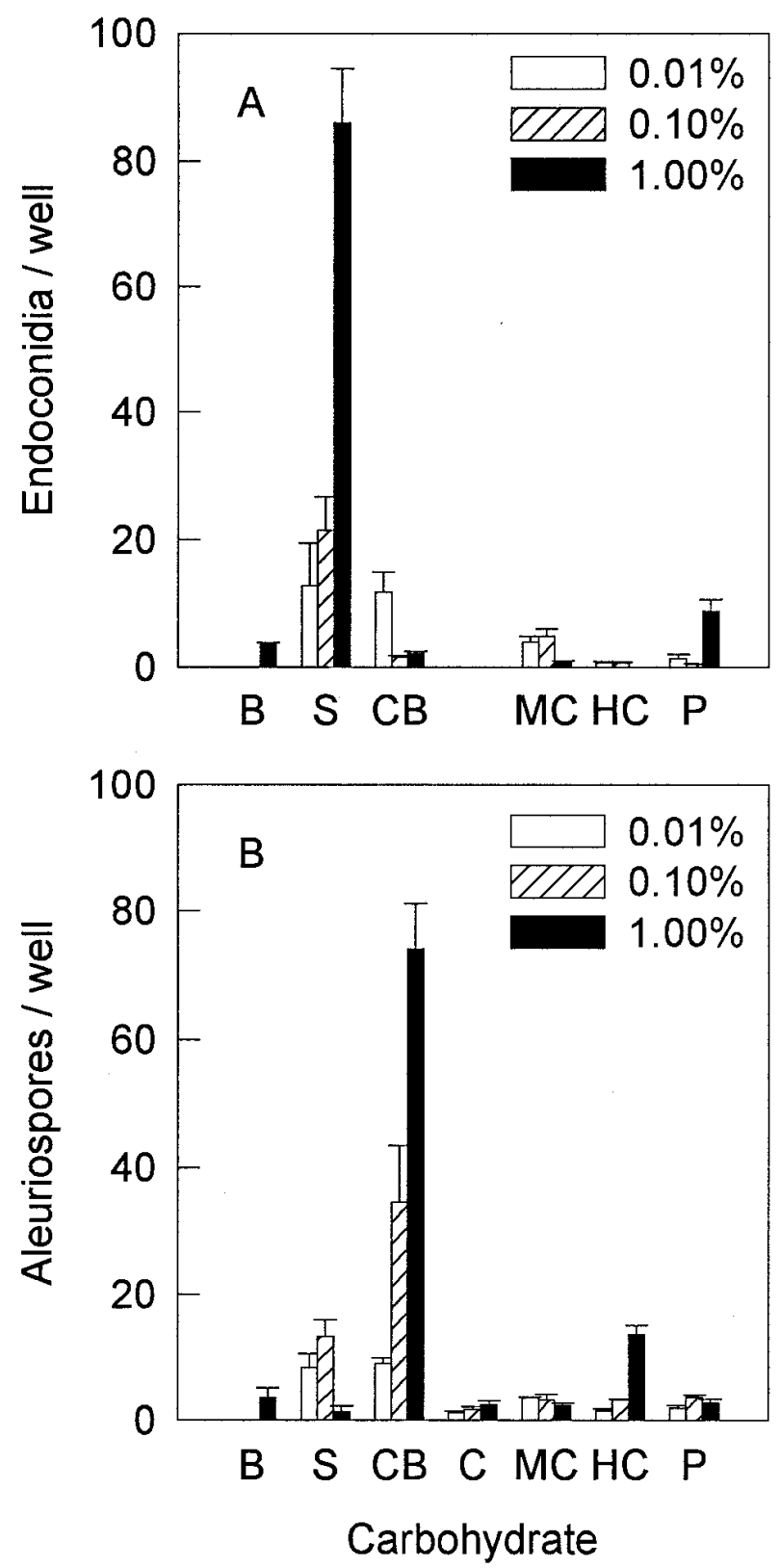

Fig. 3. Reproduction of Thielaviopsis basicola after 4 weeks of incubation in synthetic medium containing various carbohydrates. Carbohydrates added at $0.01,0.10$, and $1.00 \%$ by weight included sucrose (S), cellobiose (CB), cellulose (C), carboxymethyl cellulose (MC), hemicellulose (HC), and pectin (P). Buffer (B) alone was used as a control treatment. Error bars = standard error of the mean of eight replications. A, Production of endoconidia. Data for cellulose and the highest concentration of hemicellulose were not collected for production of endoconidia. B, Production of aleuriospores. 
(17) examined the effects of crude extract from barley straw on the interaction of $T$. basicola with host plants and concluded that the influence was upon susceptibility of the host rather than on activities of T. basicola. Patrick and Kock (26) reported similar findings following amendment of soil with decomposition products of other plants. Analysis of these reports indicates that conclusions of saprophytic behavior of T. basicola in soil should be reconsidered.

Evaluation of the ability of $T$. basicola to survive saprophytically in soil by utilization of host root tissue was a specific objective of the current study. Inoculum densities of $T$. basicola were reduced by amendment of soil with killed host roots, and the decrease was greatest in soils containing the greater amounts of the simple, soluble nutrients from the host cytoplasm. These amendments may have stimulated microorganisms with which $T$. basicola could not compete for the available substrate, or of microorganisms otherwise antagonistic to $T$. basicola. Our results suggest that, without prior parasitic association, saprophytic behavior is not exhibited by $T$. basicola in soil, even on host root tissue.

There is evidence from the literature and from the current study to suggest that $T$. basicola does not exhibit saprophytic behavior subsequent to a parasitic association or significant necrotrophic behavior during pathogenesis. Observations of parasitism by $T$. basicola support a nutritional description of this organism as a hemibiotroph $(13,21)$. The advantage of this mode of parasitism is suggested by Luttrell (18) to be one of "possession," and this hypothesis was further discussed by Parbery (25) in terms of the advantage of "position." In general, these authors suggested that one possible advantage to hemibiotrophs is that they are in close proximity to host tissue upon its natural or induced senescence and, therefore, may be able to secure the substrate before other more competitive organisms arrive. A further distinction was drawn by Parbery (25) between hemibiotrophs for which the necrotrophic phase of parasitism predominates and those for which the biotrophic phase predominates. Pathosystems such as Colletotrichum lindemuthianum on Phaseolus vulgaris typify the former type of hemibiotroph, whereas $T$. basicola may typify the latter. Parbery (25) suggested that of these two groups of hemibiotrophs there is little evidence that members of the biotrophism-predominant group utilize the host substrate following necrosis and that experimental methods to investigate this phenomenon are currently lacking.

Nutrient acquisition from dead plant tissues, either saprophytic or nectrophic, commonly involves the production of enzymes that break down the structural plant carbohydrates for utilization as a carbon source (25). Several authors have reported that $T$. basicola does not kill host cells in advance of colonization (12,38). In fact, death of intracellular hyphae of $T$. basicola was suggested to be coincident with death of the host cell based upon histological staining characteristics (5). T. basicola did not macerate or cause the structural degradation of host tissue during parasitism of tobacco in axenic culture. A similar observation was reported by Wick and Moore (38) with T. basicola on Ilex crenata in the absence of secondary microorganisms. Also, T. basicola did not have the ability to efficiently utilize structural carbohydrates as a source of carbon in the current study. Finally, the development and reproduction of hemibiotrophs following necrosis of host tissue has been considered evidence of necrotrophic nutrient acquisition $(18,25)$. A recent study of aleuriospore production, however, demonstrated that T. basicola can produce a significant number of aleuriospores utilizing only nutrient reserves held within the existing hyphae (14).

As suggested by Parbery (25), it is not possible to demonstrate the complete lack of necrotrophic behavior by hemibiotrophs such as $T$. basicola, but it is reasonable, based upon current information, to assume that necrotrophism by $T$. basicola is extremely limited if present. Also, it is likely that nutrient acquisition from root tissue is primarily from the soluble contents of the living host cytoplasm. Upon natural or induced senescence of surrounding host tissue, the inability to macerate and utilize structural plant compo- nents, the rapid diffusion of soluble compounds into the soil environment, and the close proximity of a large diversity of soilborne saprophytic competitors makes saprophytic utilization of host root tissue by $T$. basicola unlikely, even subsequent to a parasitic association.

Based on the results of this study, a close examination of previous research, and in the context of classifications proposed by Lewis (16), it appears that $T$. basicola may be most accurately described ecologically as an obligate parasite and nutritionally as a hemibiotroph in which the biotrophic phase predominates. In the recent review of the ecology of plant parasitic fungi, Parbery (25) emphasized that many pathogens previously assumed to be saprophytes and weak parasites are currently being reclassified upon further investigation of their basic biology, and he suggested that biotrophy is much more common than generally believed. T. basicola appears to fit these generalizations very well. An accurate understanding of pathogen ecology has fundamental implications to resource allocation in attempts to prevent disease, and consideration of $T$. basicola as an ecologically obligate parasite may facilitate the study of methods to control black root rot on the numerous hosts of $T$. basicola.

\section{ACKNOWLEDGMENTS}

We thank M. E. Chao for providing technical assistance.

\section{LITERATURE CITED}

1. Adams, P. B., and Papavizas, G. C. 1969. Survival of root-infecting fungi in soil. X. Sensitivity of propagules of Thielaviopsis basicola to soil fungistasis in natural and alfalfa-amended soil. Phytopathology 59:135-138.

2. Anderson, T. R., and Welacky, T. W. 1988. Populations of Thielaviopsis basicola in burley tobacco field soils and the relationship between soil inoculum concentration and severity of disease on tobacco and soybean seedlings. Can. J. Plant Pathol. 10:246-251.

3. Bateman, D. F. 1963. Influence of host and nonhost plants upon populations of Thielaviopsis basicola in soil. Phytopathology 53:1174-1177.

4. Bumbieris, M., and Lloyd, A. B. 1967. Influence of soil fertility and moisture on lysis of fungal hyphae. Aust. J. Biol. Sci. 20:103-112.

5. Christou, T. 1962. Penetration and host-parasite relationships of Thielaviopsis basicola in the bean plant. Phytopathology 52:195-198.

6. Clough, K. S., and Patrick, Z. A. 1976. Biotic factors affecting the viability of chlamydospores of Thielaviopsis basicola (Berk. \& Br.) Ferraris, in soil. Soil Biol. Biochem. 8:465-472.

7. Cooke, R. C., and Whipps, J. M. 1980. The evolution of modes of nutrition in fungi parasitic on terrestrial plants. Biol. Rev. 55:341-362.

8. Garrett, D. S. 1956. Biology of Root Infecting Fungi. Cambridge University Press, Cambridge.

9. Gayed, S. K. 1972. Host range and persistence of Thielaviopsis basicola in tobacco soil. Can. J. Plant Sci. 52:869-873.

10. Holtz, B. A., and Weinhold, A. R. 1994. Thielaviopsis basicola in San Joaquin Valley soils and the relationship between inoculum density and disease severity of cotton seedlings. Plant Dis. 78:986-990.

11. Hood, M. E., and Shew, H. D. 1996. Pathogenesis of Thielaviopsis basicola on a susceptible and a resistance cultivar of burley tobacco. Phytopathology 86:38-44.

12. Hood, M. E., and Shew, H. D. 1996. Applications of KOH-aniline blue fluorescence in the study of plant-fungal interactions. Phytopathology 86:704-708.

13. Hood, M. E., and Shew, H. D. 1997. Initial cellular interactions between Thielaviopsis basicola and tobacco root hairs. Phytopathology 87:228-235.

14. Hood, M. E., and Shew, H. D. 1997. Development of resting hyphae and aleuriospore induction of Thielaviopsis basicola. Mycologia 89:793-800.

15. Hsi, D. C. H. 1978. Effect of crop sequence, previous peanut blackhull severity, and time of sampling on soil populations of Thielaviopsis basicola. Phytopathology 68:1442-1445.

16. Lewis, D. H. 1973. Concepts in fungal nutrition and the origin of biotrophy. Biol. Rev. 48:261-278.

17. Linderman, R. G. 1970. Plant residue decomposition products and their effects on host roots and fungi pathogenic to roots. Phytopathology 60:19-22.

18. Luttrell, E. S. 1974. Parasitism of fungi on vascular plants. Mycologia 66:1-15.

19. Maier, C. R. 1961. Black root-rot development on pinto beans, incited by selected Thielaviopsis basicola isolates, as influenced by different soil temperatures. Plant Dis. Rep. 45:804-807.

20. Meyer, J., Shew, H. D., and Shoemaker, P. B. 1989. Populations of 
Thielaviopsis basicola and the occurrence of black root rot on burley tobacco in western North Carolina. Plant Dis. 73:239-242.

21. Nan, Z. B., Long, P. G., Skipp, R. A., and Hopcroft, D. H. 1992. Microscopy of invasion of red clover roots by Trichocladium basicola, and effects of benomyl and procloraz. Plant Pathol. 41:449-461.

22. Otani, Y. 1962. Studies on the black root rot disease caused by Thielaviopsis basicola (Berk \& Br.) Ferraris. Bull. Okayama Tob. Exp. Stn. 23:1-118.

23. Papavizas, G. C. 1968. Survival of root-infecting fungi in soil. VI. Effect of amendments on bean root rot caused by Thielaviopsis basicola and on inoculum density of the causal organism. Phytopathology 58:421-428.

24. Papavizas, G. C., and Adams, P. B. 1969. Survival of root-infecting fungi in soil. XII. Germination and survival of endoconidia and chlamydospores of Thielaviopsis basicola in fallow soil and in soil adjacent to germinating bean seed. Phytopathology 59:371-378.

25. Parbery, D. G. 1996. Trophism and the ecology of fungi associated with plants. Biol. Rev. 71:473-527.

26. Patrick, Z. A., and Kock, L. W. 1963. The adverse influence of phytotoxic substances from decomposing plant residues on resistance of tobacco to black root rot. Can. J. Bot. 41:747-758.

27. Reddy, M. S., and Patrick, Z. A. 1989. Effects of host, nonhost, and fallow soil on populations of Thielaviopsis basicola and severity of black root rot. Can. J. Plant Pathol. 11:68-74.

28. Schipper, B. 1970. Survival of endoconidia of Thielaviopsis basicola in soil. Neth. J. Plant Pathol. 76:206-211.

29. Shew, H. D., and Meyer, J. R. 1992. Thielaviopsis. Pages 171-174 in: Methods for Research on Soilborne Phytopathogenic Fungi. L. L. Singleton, J. D. Mihail, and C. M. Rush, eds. The American Phytopathological Society, St. Paul, MN.
30. Smith, J. G. 1960. The influence of antagonistic fungi on Thielaviopsis basicola (Berk. et Br.) Ferraris. Acta Bot. Neerl. 9:59-118.

31. Snyder, W. C., Schroth, M. N., and Christou, T. 1959. Effect of plant residues on root rot of bean. Phytopathology 49:755-756.

32. Specht, L. P., and Griffin, G. J. 1985. A selective medium for enumerating low populations of Thielaviopsis basicola in tobacco field soils. Can. J. Plant Pathol. 7:438-441.

33. Stover, R. H. 1950. The black rootrot disease of tobacco. II. Physiological specialization of Thielaviopsis basicola on Nicotiana tabacum. Can. J. Res. Sect. C Bot. Sci. 28:726-738.

34. Stover, R. H. 1956. Effect of nutrition on growth and chlamydospore formation in brown and gray cultures of Thielaviopsis basicola. Can. J. Bot. 34:459-472.

35. Subramanian, C. V. 1968. Thielaviopsis basicola. CMI (Commonw. Mycol. Inst.) Descr. Pathog. Fungi Bact. 170.

36. Tabachnik, M., DeVay, J. E., Garber, R. H., and Wakeman, R. J. 1979. Influence of soil inoculum concentrations on host range and disease reactions caused by isolates of Thielaviopsis basicola and comparison of soil assay methods. Phytopathology 69:974-977.

37. Treggi, G., Bertini, S., and Loprieno, N. 1954. Utilization of some carbon and nitrogen compounds by Thielaviopsis basicola (Berk. et Br.) Ferr. Agric. Ital. 9:36-38.

38. Wick, R. L., and Moore, L. D. 1983. Histopathology of root disease incited by Thielaviopsis basicola in Ilex crenata. Phytopathology 73:561-564.

39. Yarwood, C. E. 1974. Habitats of Thielaviopsis in California. Plant Dis. Rep. 58:54-56.

40. Yarwood, C. E. 1981. The occurrence of Chalara elegans. Mycologia 73:524-530. 